\title{
Developing your career as an anaesthetist
}

\author{
Jacqui Wise \\ London, UK
}

Anaesthetists work within, and across, many specialties and so can have a very varied and interesting career. They have the opportunity to specialise or move into management, teaching, or research.

\section{Specialising}

During the higher levels of their training anaesthetists have the opportunity to specialise. There are units available in pain medicine, ophthalmic, plastics and burns, anaesthesia in developing countries, conscious sedation in dentistry, military anaesthesia, and remote and rural anaesthesia.

At the advanced level of training trainees are able to further specialise in neuroanaesthesia, cardiothoracic anaesthesia, or paediatric anaesthesia if they want to pursue a career in a tertiary referral centre. There is also training available in intensive care medicine, pain medicine, and pre-hospital emergency medicine.

\section{Intensive care medicine}

Intensive care medicine-or critical care medicine-is the specialty with the responsibility for caring for the most critically ill patients in hospital. All anaesthetists train in intensive care medicine as part of their standard training programme.

Trainees also have the option of completing dual certificates of completion of training in anaesthesia and intensive care medicine. This normally takes eight and a half years to complete compared with the seven years of anaesthesia training. This gives anaesthetists the option of working in intensive care as a consultant lead while still practising anaesthesia. Information can be found at www.rcoa.ac.uk/special-areas-of-training/ intensive-care-medicine and from the Faculty of Intensive Care (www.ficm.ac.uk).

\section{Pain medicine}

Many doctors practise both anaesthesia and pain medicine but some choose to concentrate on pain management. During the basic and intermediate stages of training all trainees will have completed mandatory units on pain medicine. There are then optional units in higher and advanced training which are essential for those anaesthetists wanting a career in pain medicine.

During advanced training, trainees may further specialise in paediatric pain medicine, cancer pain medicine, or spinal cord stimulation. The Faculty of Pain Medicine is the professional body responsible for training, assessment, practice, and continuing professional development in this area (www.rcoa. ac.uk/faculty-of-pain-medicine/advanced-training).

\section{Pre-hospital emergency medicine}

Pre-hospital emergency medicine is a subspecialty of anaesthesia and emergency medicine approved by the General Medical Council. It covers the resuscitation and critical care of patients while they are being transferred to hospital following an injury or illness. The 12 month training programme is completed during the higher and advanced levels of training (www.rcoa.ac.uk/ careers-training/training-anaesthesia/special-areas-of-training/ the-phem-training-programme).

\section{Management}

Anaesthetists tend to gain wide experience of working across many specialties, which can stand them in good stead to move into key management roles such as clinical director or medical director. Anaesthetists also form the majority of clinicians managing intensive care units and pain management services. The Royal College of Anaesthetists runs a leadership and management course to equip doctors with the knowledge and skills in order to effect change (www.rcoa.ac.uk/education-andevents/leadership-and-management-leading-and-managingchange-0).

\section{Research}

Anaesthetists are involved in a number of research areas and are leading the development of preoperative assessment of surgical patients and the quantification of risk. The National Institute for Academic Anaesthesia has several small grants funded by the Royal College of Anaesthetists for the purpose of supporting research, education, or travel connected with the study of anaesthesia. Priority will be given to educational projects, the presentation of original work, or the provision of education to developing countries. Visit www.niaa.org.uk/article. php?newsid=89 for further information.

\section{Teaching}

Anaesthetists with an interest in medical education can teach and supervise trainees alongside their clinical work. The Royal College of Anaesthetists runs a programme of courses to support the delivery of high quality education and training in the workplace (www.rcoa.ac.uk/anaesthetists-educators-aae). The programme meets the requirements of the GMC and has been accredited by the Academy of Medical Educators. 


\section{Working abroad}

Anaesthetists have skills that are highly valued worldwide, whether in developing countries or in leading research institutions in North America or Australia. The Royal College of Anaesthetists has a global partnerships department to help and advice anaesthetists who are working or training in developing countries. The Association of Anaesthetists also has information on volunteering abroad (https://anaesthetists.org/ Home/Get-involved/Volunteering).

\section{Working part time}

Within the field of anaesthesia there is scope for flexibility in what one does and whether one works full or part time.

Anaesthetists may want to work less than full time because of family commitments or on health grounds. More information can be found at (www.rcoa.ac.uk/careers-and-training/lessfulltime-consultant-careers). 